\title{
Avaliação de um Programa de Residência Médica em Ginecologia e Obstetrícia
}

\section{Evaluation of a Medical Residency Program in Gynecology and Obstetrics}

Natalia Romano Sanchez $z^{1}(\mathbb{D})$

Cibele Isaac Saad Rodrigues ${ }^{\mathrm{I}}$ (D)

PALAVRAS-CHAVE

- Educação Médica.

- Internato e Residência.

- Avaliação Educacional.

- Ginecologia.

- Obstetrícia.

Introdução: A residência médica em ginecologia e obstetrícia é indiscutivelmente importante para a capacitação dos médicos que optam por essa especialidade dos Ministérios da Saúde e da Educação. Entretanto, as pesquisas que avaliaram esses programas de residência são escassas, especialmente no que tange a aspectos reflexivos qualitativos. Assim, este estudo descritivo e exploratório, com abordagem quantitativa e qualitativa, buscou avaliar o programa atual de residência médica em ginecologia e obstetrícia da Faculdade de Ciências Médicas e da Saúde (FCMS) da Pontifícia Universidade Católica de São Paulo (PUC-SP). Método: Como metodologia, utilizou-se a análise curricular comparativa entre o programa preconizado pela Comissão Nacional de Residência Médica até 2018 e o programa oferecido pela FCMS da PUC-SP, além de questionários autoaplicáveis a egressos do período de 2007 a 2018. Resultados: Entre os achados mais importantes da análise curricular comparativa, estão divergências sobre a disposição percentual de carga horária anual, evidenciando sobrecarga em horas de plantão, e a distribuição não equilibrada de estágios. A taxa de retorno do questionário foi de 66\% (41 dos 62 participantes). A maioria dos respondentes era do gênero feminino $(n=32,78 \%)$, com atividade predominante nas cidades de Sorocaba $(n=21,43,7 \%)$ e São Paulo $(n=10,21 \%)$. Houve preponderância de satisfação parcial do egresso com o programa cursado $(n=34,82,9 \%)$. Também foram observadas respostas que condizem com os achados da análise curricular comparativa, como a insatisfação com o número de procedimentos cirúrgicos ginecológicos realizados $(n=39,95,1 \%)$. Em relação à análise de conteúdo das questões discursivas, categorizadas segundo Bardin, houve valorização das atividades em obstetrícia pelos egressos, e as críticas mais evidentes foram relacionadas à menor quantidade de horas para certas atividades, em especial àquelas dedicadas às práticas cirúrgicas ginecológicas e atividades teóricas. Conclusões: Com base nos achados, foram propostas e acatadas pelos gestores sugestões de mudanças que devem trazer impacto positivo ao programa da residência médica. Esta pesquisa contribui para a avaliação diagnóstica de um tradicional programa de residência médica, propõe melhorias e utiliza metodologia reprodutível, podendo, assim, servir de comparação para outros estudos, de modo que avanços possam ser estabelecidos na formação do especialista. 


\section{KEYWORDS}

- Medical Education.

- Internship and Residency.

- Educational Assessment.

- Gynecology.

- Obstetrics.

\section{ABSTRACT}

Introduction: Medical residency in gynecology and obstetrics is unquestionably important in the training of physicians who choose this specialty of the Brazilian Ministries of Health and Education. However, studies evaluating these residency programs are scarce, especially regarding the reflexive qualitative aspects of the research. Therefore, this exploratory and descriptive study aimed to evaluate the current medical residency program in gynecology and obstetrics of the School of Medical and Health Sciences at Pontifícia Universidade Católica de São Paulo (PUC-SP) using a quantitative and qualitative approach. Method:The methodology included a comparative curriculum analysis between the program recommended by the National Committee of Medical Residency until 2018 and the program offered by PUC-SP School of Medical and Health Sciences, as well as a selfadministered questionnaire completed by individuals who graduated between 2007 and 2018. Results: The most significant findings of the comparative curriculum analysis include discrepancies in the percentage arrangement of annual workload, indicating an overload of on-call duty hours, and unequal distribution of internships. The questionnaire response rate was $66 \%$ (41 of 62 participants). Most respondents were women ( $n=32,78 \%$ ), who worked mainly in the cities of Sorocaba $(n=21,43.7 \%)$ and São Paulo $(n=10,21 \%)$. Most medical graduates were partially satisfied with the program $(n=34,82.9 \%)$. Some responses also matched the findings of the comparative curriculum analysis, such as dissatisfaction with the number of gynecological surgical procedures performed ( $n=39,95.1 \%)$. Regarding the content analysis of open-ended answers, categorized according to Bardin, the graduates appreciated activities in obstetrics, and the most relevant criticisms were related to fewer hours assigned to certain activities, especially those devoted to gynecological surgical practices and theoretical activities. Conclusions: Based on the findings, suggestions were proposed and accepted by the managers for changes that should have a positive impact on the medical residency program. This research contributes to the diagnostic evaluation of a traditional medical residency program in Brazil, proposes improvements, and uses reproducible methods, thus serving as a comparison basis for other studies so that advances can be made in the training of these specialists.

Recebido em 01/18/20

Aceito em 02/05/20

\section{INTRODUÇÃO}

A residência médica (RM) é modalidade de ensino de pós-graduação destinada ao treinamento em serviço supervisionado em determinada área médica. A história da RM no Brasil começou de forma irregular, caracterizada pela criação de programas sem padronização, atendendo exclusivamente às necessidades de cada instituição e serviço ${ }^{1}$. Seguindo o movimento de reivindicações dos médicos residentes, destacam-se as ações da Associação Nacional de Médicos Residentes e Associação Brasileira de Educação Médica, que tiveram papel essencial na luta para a padronização e o controle dos programas de $\mathrm{RM}^{2,3}$.

Com a criação da Comissão Nacional de Residência Médica (CNRM) em $1977^{4}$, os residentes passaram a ser legislados, e foram introduzidos benefícios, além de direitos trabalhistas fundamentais ${ }^{4,5}$. A Lei ${ }^{\circ} 6.932^{6}$ definiu a RM como a modalidade de ensino médico que confere título de especialista na área, reconhecido em todo território nacional, aos concluintes de um programa.

Atualmente a RM é considerada "padrão ouro" de especialização médica lato sensu $u^{3,7}$. A regulamentação e supervisão desses programas são articuladas por diversos órgãos hierárquicos, inseridos no Ministério da Educação (MEC) ${ }^{3}$. Para que um programa se credencie na CNRM, deve atender a todos os pré-requisitos necessários, incluindo um supervisor responsável e um grupo de preceptores sob sua coordenação, para o desenvolvimento das atividades ${ }^{4,7}$.

A percepção da necessidade de realizar mudanças na formação profissional para o fortalecimento do Sistema Único de Saúde (SUS) ${ }^{8}$ considerou a Ginecologia e Obstetrícia (GO) como um dos programas estratégicos ${ }^{8}$. Atualmente, no Brasil, a GO é área básica de conhecimento e seu Programa de Residência Médica em Ginecologia e Obstetrícia (PRMGO) tem acesso direto e duração de três anos ${ }^{4,5}$. Conforme análises de distribuição de programas de RM no país ${ }^{9,10}$, em 2011, mais da metade dos PRMGOs (54,7\%) estão na Região Sudeste ${ }^{9,10}$. Conforme dados cedidos pela Coordenação Geral de Residências em Saúde do MEC, ${ }^{11}$ havia, no primeiro semestre de 2017, 93 PRMGOs credenciados na CNRM, com 298 vagas $^{11}$.

Historicamente, a RM em GO da Faculdade de Ciências Médicas e da Saúde (FCMS) da Pontifícia Universidade Católica de São Paulo (PUC-SP) teve início em 1972. Após regulamentação e credenciamento pela CNRM em 1977, o programa recebeu aprovação periódica seguindo a legislação ${ }^{12}$, e, desde a sua criação até dezembro de 2018, formaram-se 283 especialistas, tendo atualmente oito vagas anuais credenciadas.

Apesar dos inúmeros aspectos positivos que a RM pode oferecer, foi possível vivenciar a realidade que se revela por vezes angustiante, estressante e mesmo insatisfatória ante as expectativas e ansiedades de aquisição de conhecimento, desenvolvimento de habilidades e atitudes no desenrolar da prática cotidiana. Assim, esta pesquisa objetivou avaliar, do ponto de vista dos egressos, o PRMGO da FCMS da PUC-SP e compará-lo, na prática, com aquele preconizado pela CNRM, além de conhecer o perfil do egresso, identificar e refletir se o programa atendeu às suas expectativas.

REVISTA BRASILEIRA DE EDUCAÇÃO MÉDICA

2 44 (2) : e057; 2020 


\section{MATERIAL E MÉTODOS}

Trata-se de estudo descritivo e exploratório com abordagem quantitativa e qualitativa, produto de mestrado profissional de Educação nas Profissões de Saúde pela FCMS da PUC-SP. Foi composto por duas etapas: análise documental comparativa e aplicação de questionários. A análise documental comparativa foi realizada entre o PRMGO proposto pelo MEC, segundo os pré-requisitos mínimos estipulados na Resolução da CNRM no $2 / 2006^{12}$, e aquele oferecido pela Comissão de Residência Médica (Coreme) da FCMS da PUC-SP ${ }^{13}$ em 2017. Para comparar a carga horária dos programas, optou-se por calcular o número de horas exercidas pelos residentes do PRMGO da FCMS da PUC-SP ${ }^{13}$ durante o ano de 2017. Nesse ano, o programa tinha ao todo 20 residentes, sendo oito do primeiro ano (R1), cinco do segundo (R2) e sete do terceiro (R3). Calculou-se a média de horas pelo número de médicos residentes em cada ano de treinamento.

Para cálculo de horas totais, foi realizada a média entre as horas dedicadas pelos residentes de cada ano. Para comparação da porcentagem de horas dedicadas a cada atividade, por ano da residência, calculouse a média de horas para cada uma das atividades dispostas na grade horária e estipulou-se sua porcentagem em relação à média total de horas cumpridas no ano. Para facilitar a comparação entre porcentagens, o número encontrado foi arredondado em valores absolutos, como apresentado pelo programa proposto pelo MEC.

Para obter dados significativos referentes ao PRMGO estudado, optou-se por selecionar, do total de 283 egressos do PRMGO da FCMS da PUC-SP existentes desde sua criação até 2018 , os 62 possíveis participantes que completaram o programa entre 2007 e 2018. A autora principal, por satisfazer os critérios supracitados, foi excluída da amostra a fim de evitar possível viés de seleção. Aplicou-se o critério de descontinuidade aos participantes que desistiram a qualquer tempo deste estudo, e todos os que concordaram em participar assinaram o Termo de Consentimento Livre e Esclarecido (TCLE), sendo garantido o sigilo das suas identidades.

O questionário teve como tema principal as impressões e avaliações do PRMGO feitas pelos egressos e totalizou 40 perguntas fechadas e abertas, sendo 28 sobre o tema principal e 12 sobre a caracterização sociodemográfica. Durante elaboração e antes de ser aplicado, o questionário passou por análises ortográfica e semântica realizadas por profissional especializado. Um pré-teste foi disponibilizado para sugestões e críticas a três professores de GO (experts) da mesma instituição e a dez egressos não inclusos na pesquisa. Disponibilizou-se o questionário somente após a aprovação do Comitê de Ética em Pesquisa e depois das correções sugeridas e acatadas no pré-teste.

O questionário foi disponibilizado por 56 dias na plataforma Google Forms ${ }^{\circledR}$. Todos os participantes selecionados receberam notificações por e-mail, mensagens em celular semanalmente e contato telefônico na última semana. Participaram da pesquisa 41 indivíduos, ou seja, taxa de resposta de 66\%, ambos considerados de tamanhos adequados para garantir a validade estatística da pesquisa ${ }^{14}$.

Para a análise quantitativa dos dados sociodemográficos, utilizouse o programa Stata $13.1^{\circ}$, e, para o cruzamento dos dados de respostas fechadas, adotaram-se o software de análise, testes de qui-quadrado e o teste exato de Fisher.

Já para as questões discursivas, utilizou-se a análise de conteúdo proposta por Bardin ${ }^{15,16}$. Conforme preconizado por essa técnica da análise qualitativa ${ }^{16}$, após leitura flutuante, todo material foi transcrito integralmente e lido exaustivamente para codificação e transformação do conteúdo em unidades de registro. Para uma única questão, várias subcategorias iniciais podiam estar presentes. Assim, apesar de 41 respondentes, pôde-se obter mais de 41 diferentes subcategorias que foram agrupadas e descritas em categorias válidas, objetivas, consistentes e pertinentes. Finalmente, realizou-se a interpretação reflexiva dos achados. Os participantes foram enumerados conforme ordem cronológica do envio das respostas, o que possibilitou ilustrar alguns resultados neste trabalho, mantendo o anonimato garantido no TCLE.

\section{RESULTADOS E DISCUSSÃO}

Análise documental e comparativa

Segundo a Resolução da CNRM no $2 / 2006^{12}$, foi elaborada matriz de conteúdo programático de cada especialidade de $\mathrm{RM}^{17}$. Esse programa foi analisado em comparação com o regulamento interno do PRMGO da FCMS da PUC-SP ${ }^{13}$, na sua versão mais atual. O programa proposto tem em destaque o principal objetivo a ser alcançado na formação do médico residente em GO ao final do curso programático e de seus objetivos específicos. Abrange detalhadamente as atividades teóricas e práticas e seus respectivos percentuais de carga horária a serem dedicados a cada ano de residência. $\mathrm{O}$ documento ainda recomenda processos avaliativos e expõe os requisitos mínimos a serem oferecidos.

$\mathrm{Na}$ seção sobre os conteúdos teóricos do programa proposto, há a descrição dos temas gerais e específicos de maior relevância a serem abordados. Além disso, são sugeridos vários tópicos para atualização, cursos e outras atividades teóricas que o aprendiz pode realizar. Na seção destinada a cada ano da residência, o documento expõe as habilidades a serem desenvolvidas, demonstrando ao final, em tabela, a porcentagem de carga horária a ser disposta para cada treinamento. É importante destacar que não há grandes discrepâncias numéricas na divisão das horas dedicadas às atividades durante todos os anos.

No primeiro ano da residência, o foco é nos atendimentos de baixo risco, englobando os conhecimentos em prevenção primária das doenças ginecológicas e promoção da saúde da mulher, além da fisiologia gravídico-puerperal normal, lactação e planejamento familiar puerperal. Durante o R2, o foco do aprendizado é o desenvolvimento das subáreas de GO, com atividades em ambulatórios especializados e cirurgias, iniciando sua formação em oncologia ginecológica e em obstetrícia de alto risco. A maior porcentagem do tempo do residente no R3 é destinada ao centro cirúrgico, no treinamento de cirurgias de maior complexidade e em ambulatórios especializados de ginecologia.

Já o documento da FCMS da PUC-SP mostra-se mais objetivo e prático, enfatizando comunicados importantes para o acompanhamento $\mathrm{e}$ treinamento do residente ao longo do ano, como vestimentas adequadas e documentos necessários para certos procedimentos, como o agendamento cirúrgico. Especialmente para residentes oriundos de outras instituições de ensino superior, não familiarizados com as rotinas do serviço, é importante que recebam essas orientações que facilitam sua integração. A disposição dos setores e serviços de atendimento à mulher disponíveis compõem todos os pré-requisitos exigidos pela CNRM para seu credenciamento.

Percebe-se que o regulamento da FCMS da PUC-SP não enfatiza o conhecimento e a técnica a serem adquiridos pelo residente no final de sua formação, mostrando apenas como resultado final do treinamento a

REVISTA BRASILEIRA DE EDUCAÇ̃̃o MÉDICA

3 44 (2) : e057; 2020 
possibilidade de adquirir o certificado de sua conclusão, sem dar ênfase ao objetivo pedagógico, que é a garantia do conhecimento, das habilidades e atitudes apropriados para exercer a especialidade. É possível observar certo peso hierárquico nas funções dos residentes, nas quais o R2 deve "supervisionar as atividades" dos R1 e dos internos durante atendimento médico. Já o R3 tem a função de "dirimir as dúvidas" dos demais médicos e acadêmicos. Observa-se assim um certo apagamento do papel do docente/preceptor nessas funções. O documento permite que o próprio residente se comporte, na prática, como o preceptor dos mais novos, sem considerar a importância da supervisão qualificada.

No PRMGO da PUC-SP, há a participação do próprio residente na organização da sua grade horária, principalmente referente à escala de plantões. Embora o papel do residente nessas atividades deva ser valorizado, pois o torna parte integrante e ativa do processo de construção de seu ensino e aprendizagem, é preciso lembrar que o supervisor da área, perante a Coreme, é o único responsável legal por garantir o cumprimento das atividades necessárias para a formação do residente, tendo sempre como base a Resolução da CNRM n $2 / 2006^{12}$ ou outra que venha a substituí-la e a proposição de conteúdos oferecida ${ }^{13}$.

Essa mesma resolução ${ }^{12}$ deixa a critério da Coreme de cada instituição a escolha do método de avaliação dos residentes - prova oral, escrita, prática ou de desempenho por escala de atitudes -, respeitando sempre a frequência mínima trimestral. A Coreme da PUC-SP optou por avaliar o residente conforme seu desempenho atitudinal, incluindo análise de apresentações em reuniões científicas e frequência nas atividades. Não há, porém, detalhamento do instrumento a ser utilizado, o que coloca a instituição em desacordo com o preconizado e uma oportunidade nítida de melhoria.

É importante ressaltar que métodos de avaliação diversificados aplicados aos diferentes atores envolvidos no processo de ensino e aprendizagem podem prover elementos distintos, que, em conjunto, fornecem melhor percepção sobre habilidades cognitivas, afetivas e psicomotoras de quem é avaliado e de quem avalia. Nesse processo, avaliar os residentes por pares, autoavaliação e feedback é fundamental para correção de rumos ${ }^{18}$.

Não há menção sobre qualquer modalidade de avaliação de docentes/ preceptores em ambos os documentos analisados. Isso comprova a falta de reconhecimento formal dessa atividade cada vez mais importante para a formação profissional. É preciso investir em capacitação e treinamento pedagógico para o educador que atua diretamente com médicos residentes. Devemos reconhecer a importância desse papel de educador como estratégia para aperfeiçoar os programas de residência, culminando no melhor atendimento médico e no bem-estar do paciente ${ }^{19}$.

\section{Carga horária e disposição de atividades}

A Lei $\mathrm{n}^{\circ} 6.932 / 81^{6}$ estabelece carga horária anual de 2.880 horas, distribuídas num limite de 60 horas semanais, inclusas 24 horas de plantão. Com base nela, a CNRM sugere distribuição da carga horária diferenciada para cada ano de residência, conforme o grau de complexidade de cada atividade exigida. A comparação entre carga horária e disposição de atividades segue ilustrada nos gráficos 1 e 2 .

Percebe-se uma diferença drástica entre a carga horária dos três anos (Gráfico 1). Quando se compara a disposição das atividades do R1 (Gráfico 2), percebe-se com clareza o excesso de horas dedicadas para plantão. Em 2017, o R1 completou carga horária em plantão quase quatro vezes o preconizado pela CNRM. Essa é, sem dúvida, a atividade mais divergente na comparação. Também se observa contraste importante na atividade "Centro Cirúrgico Geral e Ambulatorial".

Há atividades contempladas pelo programa de residência da FCMS da PUC-SP que não constam nas atividades propostas para o R1 pela CNRM, como "Estudo a distância (EAD)". Esta engloba a prática de estudo em regime domiciliar ou utilizando recursos oferecidos na biblioteca da faculdade sobre doença específica, designada ao residente pelo seu supervisor, a fim de padronizar e atualizar protocolos de atendimento para os serviços que são campos de estágio do programa. Essa necessidade adveio de falhas observadas por preceptores e professores na uniformização de condutas e protocolos de atendimento médico nos serviços de atendimento à mulher do SUS, vinculados à instituição. Tratase de um fator que prejudica o aprendizado do médico residente, pois o torna sujeito a variações importantes de conduta, sem a discussão do embasamento científico para as diversas opções terapêuticas.

Para o R2 (Gráfico 2), houve novamente sobrecarga de plantões, além da maior porcentagem de carga horária destinada ao "Centro Obstétrico". Também é evidente o contraste em carga horária aquém para a prática em "Ambulatórios Especializados e Unidade de Internação: Ginecologia". Essa atividade é importante para compor a bagagem teórico-prática sobre diversas doenças ginecológicas, essencial para o diagnóstico diferencial e seguimento adequado para cada paciente, conforme suas particularidades. É possível notar menor carga horária para "Urgência/Emergência”, porém entende-se que os objetivos dessa atividade sejam alcançados durante as habilidades de plantão em GO.

$\mathrm{Na}$ comparação das atividades para o R3, percebe-se importante redução na carga horária de plantão, mesmo se mantendo acima da porcentagem proposta pela CNRM (Gráfico 2). Os baixos percentuais para ambulatórios especializados em GO, também presentes nos anos anteriores, continuam evidentes no R3. Uma possível justificativa seria a menor disponibilidade de horas para os ambulatórios especializados,

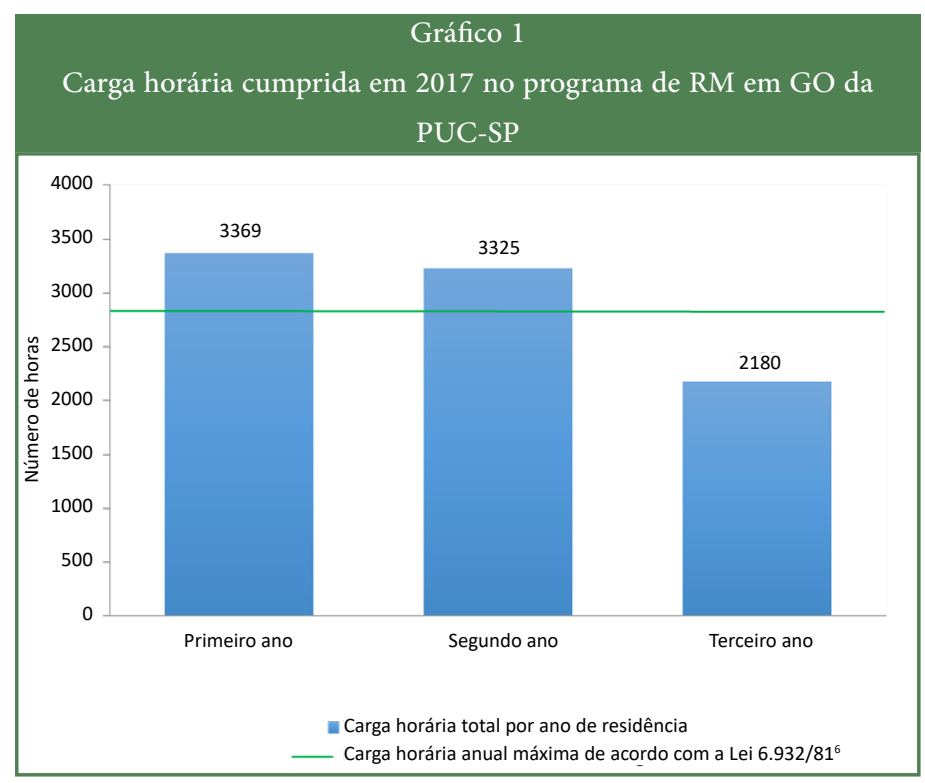

Fonte: Dados do trabalho. Autoria própria.

Carga horária realizada pelos residentes de Ginecologia e Obstetrícia da FCMS da PUCSP, no ano de 2017. A linha representa o limite de carga horária estipulado pela Lei $6.932 / 81^{6}$. 
principalmente na área da ginecologia. Há a probabilidade de o residente aprender e desenvolver habilidades nas diversas subáreas específicas, porém é pequena a frequência. Verifica-se outro contraste importante na atividade "Centro Cirúrgico", a qual não atinge a carga horária esperada.
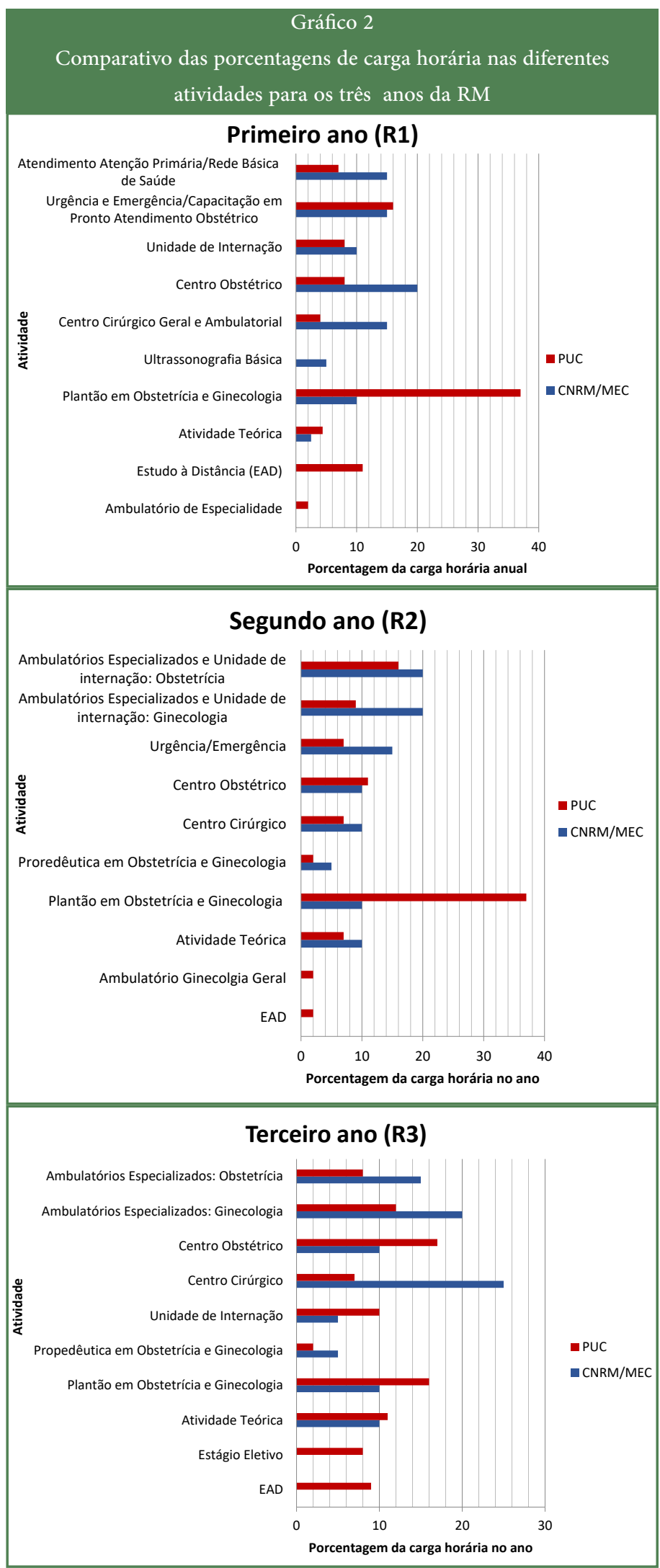

Um dos possíveis fatores, e provavelmente o mais impactante, é a insuficiência de recursos materiais, estruturais e humanos para suprir a demanda necessária, tanto para o serviço quanto para o programa.

Uma diferença no comparativo do R3, que oferece aspectos positivos à instituição, é a oportunidade de o residente adquirir experiência em estágio optativo nos diversos serviços e nas universidades conveniados à instituição, ainda dando a possibilidade de o residente adquirir vínculo novo em serviço nacional ou internacional. Essa vantagem possibilita o aprimoramento em conhecimentos de interesse pessoal do médico residente em subespecialidade, ampliando seus horizontes e auxiliando no estímulo ao estudo e à pesquisa, como já demonstrado em outros programas de residência ${ }^{20}$.

\section{Questionário}

Mulheres ( $n=32,78 \%)$, com idade entre 28 e 34 anos $(n=27,65,8 \%)$, brancas $(n=37,90,2 \%)$, com a especialidade como grau acadêmico $(n=$ $36,87,8 \%)$ e atuação em hospital privado $(n=36,87,8 \%)$ são as principais características dos respondedores. Os demais achados sociodemográficos encontram-se na Tabela 1.

As questões referentes à satisfação e insatisfação com o programa cursado revelaram que $82,9 \%(n=34)$ dos participantes se mostraram parcialmente satisfeitos, evidenciando que existem pontos a serem superados. A Tabela 2 apresenta os resultados quantitativos da pesquisa. A

\begin{tabular}{|c|c|c|}
\hline \multicolumn{3}{|c|}{ Tabela 1} \\
\hline Característica & $\mathbf{N}$ & $\%$ \\
\hline \multicolumn{3}{|l|}{ Gênero } \\
\hline Feminino & 32 & 78 \\
\hline Masculino & 9 & 22 \\
\hline \multicolumn{3}{|l|}{ Idade } \\
\hline $28-34$ & 27 & 65,8 \\
\hline $35-41$ & 14 & 34,2 \\
\hline \multicolumn{3}{|l|}{ Estado Civil } \\
\hline Casado(a) & 23 & 56 \\
\hline Solteiro(a) & 14 & 34,2 \\
\hline União Estável & 4 & 9,8 \\
\hline \multicolumn{3}{|l|}{ Etnia } \\
\hline Branca & 37 & 90,2 \\
\hline Parda & 2 & 4,9 \\
\hline Amarela & 2 & 4,9 \\
\hline \multicolumn{3}{|l|}{ Naturalidade } \\
\hline Brasileira & 40 & 97,6 \\
\hline Estrangeiro(a) & 1 & 2,4 \\
\hline \multicolumn{3}{|l|}{ Número de Filhos } \\
\hline 0 & 24 & 58,5 \\
\hline 1 & 8 & 19,5 \\
\hline 2 & 9 & 22 \\
\hline
\end{tabular}




\begin{tabular}{|c|c|c|}
\hline \multicolumn{3}{|c|}{ Continuação } \\
\hline Característica & $\mathbf{N}$ & $\%$ \\
\hline \multicolumn{3}{|l|}{ Ano de graduação em Medicina } \\
\hline $2002-2010$ & 21 & 51,2 \\
\hline $2011-2014$ & 20 & 48,8 \\
\hline \multicolumn{3}{|l|}{ Instituição Superior de graduação } \\
\hline PUC-SP & 18 & 43,9 \\
\hline Demais universidades do estado de SP & 11 & 26,8 \\
\hline Demais universidades do Brasil & 12 & 29,3 \\
\hline \multicolumn{3}{|l|}{ Cidade de atuação Profissional } \\
\hline Sorocaba & 21 & 51,2 \\
\hline São Paulo & 10 & 24,4 \\
\hline Demais Cidades & 10 & 24,4 \\
\hline \multicolumn{3}{|l|}{ Grau Acadêmico } \\
\hline Médico Especialista & 36 & 87,8 \\
\hline Pós - Graduação lato sensu & 4 & 9,8 \\
\hline Mestrado & 1 & 2,4 \\
\hline \multicolumn{3}{|l|}{ Renda Pessoal } \\
\hline $\mathrm{R} \$ 5$ mil -R\$ $15 \mathrm{mil}$ & 20 & 48,8 \\
\hline $\mathrm{R} \$ 15 \mathrm{mil}-\mathrm{R} \$ 25 \mathrm{mil}$ & 14 & 34,2 \\
\hline $\mathrm{R} \$ 25$ mil ou mais & 7 & 17 \\
\hline \multicolumn{3}{|l|}{ Local de Trabalho } \\
\hline Hospital Privado & 36 & 87,8 \\
\hline Consultório Particular & 27 & 65,9 \\
\hline Ambulatório Convênio & 26 & 63,4 \\
\hline Hospital Público & 21 & 51,2 \\
\hline Ambulatório SUS & 17 & 41,5 \\
\hline Hospital de Ensino & 11 & 26,8 \\
\hline
\end{tabular}

análise discursiva mostrou que 51,6\% $(n=32)$ das afirmações se encaixaram na categoria "Insatisfação com atuação prática do programa" e 43,55\% $(n=27)$ se referiram à "Insatisfação com organização e coordenação do programa”. Os resultados da análise qualitativa das questões abertas estão evidenciados na Tabela 3 .

Os apontamentos apresentados pelos participantes evidenciaram a importância do uso da prática médica voltada para o aprendizado, com discussão de casos e estímulo ao raciocínio clínico de forma integrada e complexa, instrumentos fundamentais para o desenvolvimento de habilidades profissionais durante a $\mathrm{RM}^{21}$. Em revisão de literatura, Botti e Rego $^{21}$ afirmam que a oferta de oportunidades clínicas variadas, que levam o aprendiz a associar seus conhecimentos à prática e evitar o automatismo com o treinamento em atributos cognitivos isoladamente, é uma das ferramentas mais importantes para a construção do raciocínio clínico de qualidade durante a $\mathrm{RM}^{21}$.

\begin{tabular}{|lcc}
\multicolumn{2}{c}{ Tabela 2} & \\
\multicolumn{1}{c}{ Resultados análise quantitativa das questões objetivas } \\
\multicolumn{1}{c}{ Tema abordado } & N & $\%$ \\
\hline Satisfação com o Programa cursado & 34 & 83 \\
Parcialmente satisfeito(a) & 6 & 14,6 \\
Integralmente satisfeito(a) & 1 & 2,4
\end{tabular}

O programa foi previamente apresentado

$\begin{array}{lcc}\text { Sim, parcialmente } & 19 & 46,3 \\ \text { Não } & 12 & 29,3 \\ \text { Sim, integralmente } & 10 & 24,4 \\ \text { As formas avaliativas foram previamente apresentadas } & \\ \text { Não havia qualquer tipo de avaliação } & 19 & 46,3 \\ \text { Não } & 12 & 29,3 \\ \text { Sim, parcialmente } & 8 & 19,5 \\ \text { Sim, integralmente } & 2 & 4,9\end{array}$

Pensou em desistir do Programa ao longo do curso

$\begin{array}{lll}\text { Não } & 24 & 58,5\end{array}$

Havia acompanhamento de Preceptor/Professor durante atendimento médico $\begin{array}{lll}\text { Maioria das vezes } & 23 & 56,1\end{array}$

$\begin{array}{lll}\text { Algumas vezes } & 14 & 34,1\end{array}$

Sempre

4

Houve orientação educativa na discussão de casos

Maioria das vezes $23 \quad 56,1$

$\begin{array}{lll}\text { Algumas vezes } & 15 & 36,6\end{array}$

$\begin{array}{lll}\text { Sempre } & 2 & 4,9\end{array}$

$\begin{array}{lll}\text { Nunca } & 1 & 2,4\end{array}$

Houve descanso pós plantão

$\begin{array}{lll}\text { Algumas vezes } & 17 & 41,5\end{array}$

$\begin{array}{lll}\text { Maioria das vezes } & 11 & 26,7\end{array}$

$\begin{array}{lll}\text { Nunca } & 9 & 22\end{array}$

$\begin{array}{lll}\text { Sempre } & 4 & 9,8\end{array}$

Houve atividade teórica semanalmente

$\begin{array}{lll}\text { Algumas vezes } & 17 & 41,5\end{array}$

Sempre $14 \quad 34,1$

$\begin{array}{lll}\text { Maioria das vezes } & 8 & 19,5\end{array}$

$\begin{array}{lll}\text { Nunca } & 2 & 4,9\end{array}$

Os residentes participavam das atividades teóricas

$\begin{array}{lll}\text { Algumas vezes } & 19 & 46,3\end{array}$

$\begin{array}{lll}\text { Maioria das vezes } & 18 & 43,9\end{array}$

$\begin{array}{lll}\text { Sempre } & 2 & 4,9\end{array}$

$\begin{array}{lll}\text { Nunca } & 2 & 4,9\end{array}$

Continua... 


\begin{tabular}{|c|c|c|}
\hline \multicolumn{3}{|c|}{ Tabela 2} \\
\hline Tema abordado & $\mathbf{N}$ & $\%$ \\
\hline \multicolumn{3}{|c|}{ Média de horas semanais de atividade teórica } \\
\hline $2 \mathrm{~h}$ & 17 & 41,5 \\
\hline $4 \mathrm{~h}$ & 10 & 24,4 \\
\hline $1 \mathrm{~h}$ & 7 & 17,1 \\
\hline $3 \mathrm{~h}$ & 5 & 12,1 \\
\hline Oh & 2 & 4,9 \\
\hline
\end{tabular}

Foi oferecido aprendizado com tecnologias que auxiliam no diagnóstico/ tratamento de patologias em GO

$\begin{array}{lcc}\text { Algumas vezes } & 33 & 80,5 \\ \text { Nunca } & 6 & 14,6 \\ \text { Maioria das vezes } & 2 & 4,9 \\ \text { Sempre } & 0 & 0 \\ \text { Considerou número de procedimentos obstétricos apropriado para } \\ \text { aprendizado } \\ \text { Sim } \\ \text { Não } & 37 & 90,2 \\ \text { Com } & 4 & 9,8\end{array}$

Considerou número de procedimentos ginecológicos apropriado para aprendizado

$\begin{array}{lcc}\text { Não } & 39 & 95,1 \\ \text { Sim } & 2 & 4,9 \\ \text { Houve estímulo para pesquisa científica durante o Programa } & \\ \text { Nunca } & 22 & 53,6 \\ \text { Algumas vezes } & 17 & 41,5 \\ \text { Maioria das vezes } & 2 & 4,9 \\ \text { Sempre } & 0 & 0\end{array}$

Artigo publicado em periódico durante o Programa

$\begin{array}{lcc}\text { Não } & 38 & 92,7 \\ \text { Sim } & 3 & 7,3 \\ \text { Artigo publicado em periódico após o Programa } & \\ \text { Não } & 34 & 82,9 \\ \text { Sim } & 7 & 17,1\end{array}$

Trabalho apresentado em evento científico durante o Programa

\begin{tabular}{lcc} 
Não & 28 & 68,3 \\
Sim & 13 & 31,7 \\
\hline \multicolumn{2}{l}{ Trabalho apresentado em evento científico após o Programa } & \\
Não & 32 & 78 \\
Sim & 9 & 22
\end{tabular}

\begin{tabular}{|c|c|c|}
\hline $\begin{array}{c}\text { Tabela } 3 \\
\text { Análise qualitativa das respostas discurs }\end{array}$ & vas do questio & \\
\hline Categorias para cada tema abordado & $\begin{array}{l}\text { Número de } \\
\text { observações }\end{array}$ & $\%$ \\
\hline Satisfação com o Programa cursado & & \\
\hline Insatisfação com atuação prática do programa & 32 & 51,61 \\
\hline $\begin{array}{l}\text { Insatisfação com organização e coordenação do } \\
\text { programa }\end{array}$ & 27 & 43,55 \\
\hline Satisfação com a formação na residência & 3 & 4,84 \\
\hline Motivos para pensar em desistir do Programa & & \\
\hline Desgaste físico & 16 & 57,14 \\
\hline Desgaste emocional & 7 & 25 \\
\hline $\begin{array}{l}\text { Incompatibilidade entre expectativa e realidade } \\
\text { encontrada }\end{array}$ & 5 & 17,86 \\
\hline Acompanhamento de Professor/Preceptor no ater & dimento médic & \\
\hline $\begin{array}{l}\text { Atendimento sem acompanhamento, dando } \\
\text { autonomia ao residente }\end{array}$ & 9 & 42,86 \\
\hline $\begin{array}{l}\text { Atendimento acompanhado pelo residente mais } \\
\text { antigo }\end{array}$ & 6 & 28,57 \\
\hline $\begin{array}{l}\text { Presente nos diferentes cenários, exceto } \\
\text { plantões }\end{array}$ & 3 & 14,29 \\
\hline $\begin{array}{l}\text { Presente nos diferentes cenários, exceto } \\
\text { ambulatórios }\end{array}$ & 3 & 14,29 \\
\hline
\end{tabular}

Orientação educativa na discussão de casos com Professor/Preceptor

Foco da discussão era somente para o

andamento do serviço

Tarefa dedicada somente por alguns

Professores/Preceptores

3

Participação ou não dos residentes em atividades teóricas

Proibição da docência/preceptoria 16

Falta de interesse do residente pelo tema da aula

Posição hierárquica

Foi oferecido aprendizado com tecnologias que auxiliam no diagnóstico/ tratamento de patologias em GO

Estruturação deficiente do programa para as atividades

Disponibilidade limitada de material para essas atividades

Má disposição docente para essas atividades

2

10,53

Motivos para considerar procedimentos em GO apropriados ou inapropriados para o aprendizado

Poucas oportunidades de treinamento na grade horária do Programa

Impedimentos cirúrgicos

11

Pouco número de Professores/Preceptores

disponíveis para essas atividades

\section{0}




\section{Tabela 3 \\ Continuação}

Categorias para cada tema abordado

\section{Número de} observações

Motivos para frequência de estímulo em pesquisas científicas durante o Programa

Pouco estímulo dos Preceptores/Professores

O interesse sempre partia do residente 16,67

Fortalezas do R1

Assistência ao parto

70

Grande volume de atendimentos

Aprendizado em urgência e emergência

5

1

Fortalezas do R2

Aprendizado em subespecialidades obstétricas

Amadurecimento pessoal e profissional

35

12

24

3

6

Aprendizado em subespecialidades ginecológicas

Redução de carga horária em relação ao ano

anterior

Aprendizado cirúrgico

Não teve ponto forte a ser mencionado

Fortalezas do R3

Procedimentos cirúrgicos de média e alta complexidade

Prática obstétrica

Prática em subespecialidades em GO

Amadurecimento pessoal e profissional

Não teve ponto forte a ser mencionado

Diminuição da carga horária em relação ao ano anterior

Fragilidades do R1

Falta de acompanhamento, supervisão e orientação pela preceptoria/docência

Pouca dedicação a suporte teórico durante o ano

Desgaste físico e emocional devido à carga

horária

Pouca prática em ginecologia ambulatorial

Não ter participação ativa nos procedimentos

cirúrgicos

Pouca prática obstetrícia na atenção primária

Não teve ponto fraco a ser mencionado

Fragilidades do R2

Pouca prática cirúrgica

Pouca prática em ginecologia

Pouca dedicação a suporte teórico durante o ano

Falta de organização, supervisão e orientação

da preceptoria/docência

Pouca prática em atividades de baixo risco

Não teve ponto fraco a ser mencionado
17

13

23,21

21,43

10,71

5,36

3,57

2

26,15

6

1

3,08

26

43,33

12

20

11

18,33

6

10

4

6,67

1,67
Continua...

\begin{tabular}{|c|c|c|}
\hline \multicolumn{3}{|l|}{$\begin{array}{c}\text { Table } 3 \\
\text { Continuação }\end{array}$} \\
\hline Categorias para cada tema abordado & $\begin{array}{l}\text { Número de } \\
\text { observações }\end{array}$ & $\%$ \\
\hline \multicolumn{3}{|l|}{ Fragilidades do R3 } \\
\hline Pouca prática cirúrgica & 19 & 32,76 \\
\hline Pouca prática em ginecologia & 15 & 25,86 \\
\hline $\begin{array}{l}\text { Falta de organização da grade horária do } \\
\text { programa }\end{array}$ & 9 & 15,52 \\
\hline $\begin{array}{l}\text { Pouca dedicação a suporte teórico durante o } \\
\text { ano }\end{array}$ & 8 & 13,79 \\
\hline $\begin{array}{l}\text { Falta de supervisão e orientação da preceptoria/ } \\
\text { docência }\end{array}$ & 7 & 12,07 \\
\hline \multicolumn{3}{|l|}{ Sugestões de melhorias dadas pelos participantes } \\
\hline $\begin{array}{l}\text { Melhorar estruturação e organização do } \\
\text { programa }\end{array}$ & 59 & 45,38 \\
\hline $\begin{array}{l}\text { Planejamento educativo com ênfase no } \\
\text { aprendizado para cada ano }\end{array}$ & 26 & 20 \\
\hline $\begin{array}{l}\text { Aumentar o estímulo e a produção científica } \\
\text { com a participação conjunta entre professores, } \\
\text { preceptores, residentes e alunos }\end{array}$ & 21 & 16,15 \\
\hline $\begin{array}{l}\text { Capacitação pedagógica e atualização da } \\
\text { preceptoria que atua nos serviços contidos no } \\
\text { programa }\end{array}$ & 15 & 11,54 \\
\hline $\begin{array}{l}\text { Incorporar técnicas de avaliação e feedback } \\
\text { construtivo }\end{array}$ & 7 & 5,38 \\
\hline Nenhuma sugestão de mudança & 2 & 1,54 \\
\hline
\end{tabular}

Ao serem questionados sobre desistência durante a RM, 41,5\% $(n=17)$ dos entrevistados responderam que já pensaram em desistir (Tabela 2). Isso mostra que muitos egressos enfrentaram dificuldades que consideraram significativas o suficiente a ponto de repensarem sobre sua permanência no programa. A análise qualitativa revelou características consideradas negativas pelos egressos, como "Desgaste físico" com 57,14\% $(n=16)$ das observações, reputada como a mais importante. O número aumentado de horas dedicadas a plantões certamente causa impacto negativo no residente. O desgaste emocional representou 25\% $(n=7)$ das afirmações encontradas na questão. Estudos evidenciaram que o programa de residência, por si só, é fonte de tensão e estresse para o residente ${ }^{22}$. As taxas de burnout, depressão, irritabilidade e ansiedade são maiores entre médicos no período da residência ${ }^{23}$.

A afirmação "Assédio moral” registrada pelo participante no 11 merece destaque. Apesar do resultado pouco frequente, evidências mostram que o assédio moral é comumente encontrado no ambiente hospitalar e nos programas de $\mathrm{RM}^{24}$. Se houvesse uma questão específica sobre assédio durante o curso, seria provável verificar um número maior do que o encontrado. Sua definição é difícil por conta das possíveis interpretações de uma grande diversidade de atos e comportamentos abusivos. $\mathrm{O}$ assédio moral ocorre frequentemente em cenários institucionais fechados, com prevalência hierárquica assimétrica, onde suas ações são comumente conduzidas silenciosamente ${ }^{24,25}$. Considerando o ambiente da RM, esse silenciamento acontece em ambos os personagens (abusador e abusado). 
O interesse do médico aprendiz em garantir maiores oportunidades de prática e melhor ensinamento de seus mestres o coloca em situação de maior vulnerabilidade, podendo estar suscetível a ações de abuso e conduzi-las de maneira reservada, com intuito de preservar seu aprendizado. Isso pode trazer consequências impactantes para o futuro do profissional, como mostram evidências que comprovam a maior tendência a transtornos psiquiátricos e abusos com pacientes entre aqueles profissionais assediados ${ }^{25}$. Em outras ocasiões, a sensação de ter a obrigação de se apresentar como profissional incabível de falhas pode trazer sentimentos como frustração e angústia ao preceptor, sendo esses muitas vezes projetados durante o processo de ensino, camuflados em cobranças e críticas feitas ao residente ${ }^{25}$. Os mecanismos envolvidos nas relações de abuso no ambiente médico e em especial na RM são certamente mais extensos, sendo seu maior aprofundamento de extrema importância ${ }^{25}$.

As questões sobre estrutura e organização do programa evidenciaram que a falta da apresentação formal prévia do programa, parcial ou plena, foi registrada por um percentual acumulado de 75,5\% $(n=31)$ dos entrevistados (Tabela 2). Não oferecer a possibilidade de o residente conhecer, entender e esclarecer dúvidas sobre o programa em que ingressou pode gerar sentimentos como angústia, medo e frustração, gerando impacto em seu desempenho e qualidade de vida ${ }^{26}$. Quase metade $(41,5 \%$, $n=17$ ) dos egressos afirmou ter descanso após o plantão algumas vezes. Uma possível explicação para esse achado é a norma ter sido considerada obrigatória a partir da sua publicação em $2011^{27}$, podendo esse resultado ser atribuído aos participantes que frequentaram o programa antes dessa data. Além disso, possíveis reposições de residentes que deixam lacunas nas atividades de atendimento poderiam ter sido motivo para que egressos tenham deixado de cumprir as horas de descanso.

Uma grande maioria ( $n=33,80,5 \%)$ referiu ter recebido treinamento com tecnologias auxiliares no diagnóstico e tratamento de doenças em GO, como ultrassonografia, histeroscopia e estereotaxia, apenas algumas vezes. A análise qualitativa mostrou prevalência $(63,16 \%, n=12)$ de respostas discursivas para "Estruturação deficiente do programa para as atividades" (Tabela 3). A resposta transcrita "Não tínhamos nenhum estágio voltado para esses tipos de exames. Apenas no R3 acompanhamos biópsias de mama, por exemplo" (participante $n^{\circ} 20$ ) exemplifica a dificuldade estrutural. Por serem cada vez mais frequentes no cotidiano dos grandes serviços, principalmente em hospitais-escola de alta complexidade, é necessário o ensinamento básico sobre essas tecnologias, especialmente referente ao conhecimento teórico. É a partir desse contato inicial que o médico, após concluir a especialização, pode optar por aprofundar-se em treinamentos específicos que agregam saberes à sua formação, como cursos lato sensu propostos por algumas instituições ${ }^{28}$.

Ao avaliar se o número de procedimentos cirúrgicos foi adequado para sua formação, foi encontrado que $90,2 \%(n=37)$ considerou apropriado somente para os obstétricos. A maioria $(n=39,95,1 \%)$ revelou frequência de cirurgias ginecológicas inapropriada para o aprendizado (Tabela 2). Quando se analisaram as justificativas para essa questão, percebeu-se que $62,5 \%(n=25)$ se referem a "Poucas oportunidades de treinamento na grade horária do programa" (Tabela 3). Esse resultado ganha força quando relacionado aos achados da análise comparativa de distribuição de atividades, confirmando a afirmativa. Somadas a "Impedimentos cirúrgicos" $(27,5 \%, n=11)$, as duas justificativas acumulam $90 \%(n=36)$ das afirmações. A frase transcrita "Pouca carga horária de cirurgia em ginecologia. Cancelamentos de cirurgias eram frequentes" (participante $\left.n^{\circ} 23\right)$ mostra a realidade enfrentada pela maioria.

Quando questionados sobre a avaliação na residência, quase metade dos entrevistados $(n=19,46,3 \%)$ respondeu não ter tido qualquer tipo de avaliação durante o curso. Uma possível justificativa para tal resultado seria o desconhecimento do residente sobre os instrumentos utilizados pelo programa, descritos no regulamento, o que significa que ele pode ter passado por avaliação (de frequência ou comportamento e atitude) sem perceber. Outra possível explicação seria a escassez de profissionais aptos, especialmente entre os preceptores de campo, nem sempre motivados ou capacitados para realizar processos avaliativos com feedback.

O grande número de horas de plantão no programa faz com que o plantonista do serviço atue frequentemente como preceptor e, apesar de possuir formação profissional especializada e tempo de experiência no exercício da medicina, não dispõe dos saberes pedagógicos necessários para exercer adequadamente as tarefas de supervisão, correção, ensino e avaliação do médico residente. O despreparo para as funções e a falta de comunicação e fiscalização da instituição tornam o processo de ensinoaprendizagem defasado e desvalorizado ${ }^{29,30}$.

É compreensível o fato de que, dos 30 entrevistados que afirmaram ter passado por avaliação, a maioria respondeu que não teve avaliações somativas $(n=27,90 \%)$ e nem formativas $(n=21,70 \%)$, uma vez que o programa não exige outros métodos avaliativos além do desempenho atitudinal e da frequência. Outro resultado importante é encontrado na pergunta sobre feedback, que demonstrou fragilidade significativa, após revelar que $83 \%(n=25)$ daqueles que responderam ter passado por avaliação não tiveram qualquer tipo de feedback.

Sabe-se da importância da presença da avaliação no desenvolvimento de habilidades e conhecimentos ${ }^{29,30}$. O que deve ser refletido são os métodos avaliativos utilizados atualmente nos programas de RM. É preciso conhecer as vantagens e desvantagens dos diversos métodos ${ }^{30}$ para usar aquele mais adequado para cada habilidade a ser avaliada. Segundo Nunes, Michel, Haddad, Brenelli e Oliveira ${ }^{31}$, o residente deve ser avaliado multidimensionalmente, desde o conhecimento e desempenho prático até a capacidade de comunicação/relação com pacientes, e saber trabalhar em equipe com responsabilidade, ética, comprometimento social e de acordo com as políticas de saúde ${ }^{30}$.

Com relação à prática, $56,1 \%$ dos egressos $(n=23)$ consideraram que o acompanhamento de professor ou preceptor durante atendimento médico aconteceu na maioria das vezes. A análise qualitativa mostrou que 42,86\% $(n=9)$ das afirmações compõem a categoria "Atendimento sem acompanhamento, dando autonomia ao residente", seguida de "Atendimento acompanhado somente pelo residente mais antigo", com 28,57\% $(n=5)$ das observações. Percebe-se a força da hierarquia no ambiente da prática médica nesse programa, o que é evidente tanto nas normas quanto nos recortes dos egressos: "No R1, que é quando estamos aprendendo, o mais próximo de nós é o R2. O chefe muitas vezes se faz inacessível com a desculpa de hierarquia e, assim, segue o primeiro e mais importante ano de formação do especialista" (Participante $\mathrm{n}^{\circ} 19$ ).

Quanto à orientação educativa, $56,1 \%(n=23)$ dos participantes afirmaram que, durante o atendimento médico, ela ocorria na maioria das vezes e $36,6 \%(n=15)$ referiram frequência menor (algumas vezes). A maioria das justificativas $(n=5,62,5 \%)$ manteve-se na categoria "Foco da discussão era somente para o andamento do serviço”. Evidências mostram

REVISTA BRASILEIRA DE EDUCAÇÃO MÉDICA

9 44 (2) : e057; 2020 
que a grande demanda de atendimento e a excessiva carga horária de trabalho são os principais obstáculos enfrentados por docentes num programa de $\mathrm{RM}^{31}$. Esses aspectos, somados ao baixo reconhecimento da profissão, com consequente baixa remuneração, precariedade das condições de trabalho e constante desafio em despertar a curiosidade e interesse no aprendiz culminam em desapontamentos no exercício da profissão que desestimulam o profissional ${ }^{31}$.

Sobre a frequência das atividades teóricas, 41,5\% $(n=17)$ dos entrevistados afirmaram que elas aconteciam apenas algumas vezes (Tabela 2). Quando questionados sobre a sua participação nas atividades teóricas, $46,3 \%(n=19)$ responderam que o faziam em algumas vezes. A análise discursiva para a justificativa revelou predomínio $(n=16,80 \%)$ das observações para "Proibição da docência/preceptoria" (Tabela 3). Percebe-se, assim, que as atividades teóricas ficam em segundo plano, sendo cumpridas em ocasiões especiais (permissão da preceptoria/ docência, assunto de interesse do residente e posição hierárquica favorável). Entende-se que a essência do programa de RM é a atuação prática, porém deve-se lembrar da importância em associar a teoria ao exercício como base para o aperfeiçoamento do raciocínio clínico e da expertise médica ${ }^{21}$. Essa análise torna compreensível a variedade de carga horária semanal encontrada entre os entrevistados (Tabela 2).

Ao avaliarem o estímulo à produção científica durante o programa, $53,7 \%(n=22)$ dos entrevistados referiram ter sido nulo ("nunca"). Em análise cruzada com dados obtidos em "grau acadêmico", não se obteve significância ( $p$ $=0,107)$. Porém, é possível perceber certa tendência entre aqueles egressos cujo estímulo à pesquisa foi reduzido ou inexistente a não progredirem para outros títulos de graduação. A análise discursiva revelou que somente uma observação (16,67\%) mencionava o interesse do residente como fator causador do pouco estímulo à pesquisa, e $83,33 \%(n=5)$ se referiram à categoria "Pouco estímulo por parte dos preceptores/professores" (Tabela 3 ).

O baixo número de respostas discursivas para esta questão dificultou sua discussão, porém estudos relacionados ${ }^{32,33}$ mostram fatores desencorajadores para a prática acadêmica, como questões burocráticas relacionadas à pesquisa, tempo insuficiente de treinamento em pesquisa $\mathrm{e}$ questões financeiras. Entre os fatores que tiveram importância na escolha da carreira acadêmica, estão a admiração pelos professores-orientadores, as experiências de ensino vivenciadas com os estudantes de Medicina e a apresentação de trabalho em evento científico. Conhecer os fatores que podem estimular e limitar a prática médica em pesquisas durante a residência é uma importante estratégia para fortalecer o meio científico de uma instituição ${ }^{32,33}$, apesar de ser questionável o período destinado à RM como ideal para a prática em trabalhos científicos, haja vista a grande demanda de aprendizado técnico especializado destinada ao residente, especialmente no primeiro ano do programa.

A grande maioria dos egressos não publicou nenhum artigo científico em revista durante $(n=38,92,7 \%)$ ou após o término do programa $(n=$ $34,82,9 \%)$. Resultados parecidos foram encontrados para a apresentação de trabalhos científicos em eventos na área (Tabela 2). Esses dados podem indicar o perfil do profissional formado por esse programa, sendo ele voltado mais ao mercado de trabalho do que à pesquisa.

Os resultados qualitativos sobre as fortalezas do programa revelaram que as atividades obstétricas têm grande relevância para o aprendizado durante os três anos de RM. Apesar de afirmações negativas sobre excessiva carga horária de plantão e suas consequências, essa característica foi aproveitada pelos egressos, de modo que a intensa prática obstétrica se tornou a principal fortaleza do programa (Tabela 3). O aprendizado em subespecialidades é valorizado no R2 e R3, bem como o amadurecimento pessoal e profissional. Há um grande aproveitamento das atividades em centro cirúrgico no terceiro ano (35,71\%), apesar de a carga horária ser considerada inferior àquela proposta pela CNRM (Tabela 3).

As fragilidades mais frequentemente apontadas pelos egressos para cada ano foram "Falta de acompanhamento, supervisão e orientação da preceptoria/docência" durante o R1, e predominaram as afirmações sobre "Pouca prática cirúrgica" e "Pouca prática em ginecologia ambulatorial" para os dois últimos anos. Observou-se também percentual menor, porém relevante, para as categorias "Falta de organização da grade horária do programa", "Pouca dedicação a suporte teórico durante o ano" e "Falta de supervisão e orientação da preceptoria/docência” no R3. Essas três categorias dizem respeito às principais atividades designadas à coordenação do programa. Esses resultados revelam importante diagnóstico estrutural do programa e podem servir de direcionamento para possíveis ajustes no futuro.

A análise das respostas discursivas sobre sugestões de mudança (Tabela 3) revelou que 45,38\% $(n=59)$ das observações se referiram a "Melhorar estruturação e organização do programa". As diferenças encontradas na disposição de carga horária para as atividades de cada ano, quando comparadas com o proposto pela CNRM, e a extensa carga horária de plantão observada no primeiro e segundo anos vão ao encontro desses achados e refletem obstáculos administrativos. Em "Planejamento educativo com ênfase no aprendizado para cada ano" ( $n=26,20 \%)$, houve sugestões que se referiram à valorização do aprendizado do residente acima do andamento do serviço: "Carga horária melhor distribuída, aulas teóricas, provas de avaliações, staffs mais presentes e interessados em contribuir para o ensino" (Participante $n^{\circ} 31$ ).

Com essas afirmações, os egressos tentam mostrar a importância da dedicação educacional à própria formação e como isso foi, de alguma maneira, negligenciado durante a vivência que tiveram no programa. A categoria "Aumentar o estímulo e a produção científica com a participação conjunta entre professores, preceptores, residentes e alunos", com 16,15\% $(n=21)$ das observações, mostra que, apesar de a maioria dos entrevistados não apresentar produções científicas, essa atividade é valorizada. A "Capacitação pedagógica e atualização da preceptoria que atua nos serviços contidos no programa" acumulou 11,54\% ( $n=$ 15) das observações e configura-se como uma estratégia fundamental para o melhor êxito no processo de ensino-aprendizagem do residente. $\mathrm{O}$ fornecimento das ferramentas adequadas para a transmissão de conhecimentos e treinamento prático, importantes para um educador, aumenta a probabilidade de sucesso no desenvolvimento e na aquisição da expertise médica da especialidade ${ }^{31,21}$.

\section{CONCLUSÕES}

A análise documental e comparativa da distribuição de atividades do programa atual com o preconizado permitiu um melhor mapeamento do programa estudado, evidenciando características positivas, como a presença de estágio eletivo e a dedicação a estudos sobre protocolos de atendimento. Porém, existem aspectos potencialmente prejudiciais ao aprendizado, como excessiva carga horária para plantão e déficits em horas dedicadas a certas atividades, como centro cirúrgico e ambulatório de especialidades. Sugere-se que alguns tópicos sejam revistos, como

\footnotetext{
$10 \mid$\begin{tabular}{l|l} 
REVISTA BRASILEIRA DE EDUCAÇÃO MÉDICA \\
\hline 44 (2) : e057; 2020
\end{tabular}
} 
redistribuição de carga horária e instituição da avaliação para aprendizes e educadores, para que melhorias na qualidade do ensino e da formação do especialista possam ser atingidas.

Apesar de a porcentagem de retorno (66\%) ter possibilitado a validação dos resultados, reconhecemos que o número de participantes que responderam ao questionário (41) foi fator limitante para aquisição de resultados ainda mais significativos, principalmente para obtenção de dados cruzados. Foi possível refletir sobre aspectos que causam impacto na formação do especialista. Talvez maiores estudos possam proporcionar mais informações que enriqueçam a discussão sobre aspectos que causam impressões positivas e negativas nos egressos, como relações entre colegas, educadores, funcionários dos serviços da saúde e seus pacientes, bem como sobre desafios médicos, éticos e legais que a especialidade pode trazer.

A não inclusão da análise e discussão sobre aquisição ou não, desempenho e índices de aprovação e reprovação para o título de especialista fornecido pela Federação Brasileira de Ginecologia e Obstetrícia (Febrasgo) representa uma limitação deste estudo, já que esses dados poderiam fornecer informações adicionais sobre o perfil profissional do egresso. Por ser exame reconhecido nacionalmente e ter volumoso repertório de avaliações ao longo dos anos, seus dados potencialmente poderiam fornecer subsídios que direcionassem a criação de estratégias para melhorar a atenção à saúde da mulher, além de auxiliar na busca por aprimoramento no ensino dos programas de residência.

Com base nos achados, foram propostas e acatadas pelos gestores sugestões de mudanças que devem promover impacto positivo no ensino da residência. Esta pesquisa contribui para a avaliação diagnóstica de um tradicional programa de RM, propõe melhorias, utiliza metodologia reprodutível e, assim, pode servir de comparação para outros, a fim de que avanços possam ser estabelecidos na formação do especialista.

\section{AGRADECIMENTOS}

A todos que, de alguma forma, contribuíram para a realização deste trabalho.

\section{REFERENNCIAS}

1. Martins LAN. Residência médica: estresse e crescimento. São Paulo: Casa do Psicólogo; 2005.

2. Miranda Júnior UJP. Comissão Nacional de Residência Médica: caminhos e descaminhos na gestão desta modalidade de especialização médica no Brasil [dissertação]. Rio de Janeiro: Fundação Getulio Vargas; 1997.

3. Michel JLM, Oliveira RAB, Nunes MPT. Residência médica no Brasil. Cad ABEM 2011;7:7-12.

4. Brasil. Decreto ${ }^{\circ} 91.364$, de 21 de junho de 1985. Altera a redação do $\$ 1^{\circ}$ do artigo $2^{\circ}$ do Decreto no $80.281 / 77$, que dispõe sobre a constituição da Comissão Nacional de Residência Médica. Diário Oficial da União 22 jun1985; Seção 1, p. 8793 [acesso em 12 nov 2019]. Disponível em: https://www.infectologia.org.br/admin/ zcloud/89/2016/06/d91364.pdf.

5. Brasil. Ministério da Educação e Cultura. Secretaria de Educação Superior. Comissão Nacional de Residência Médica. Resolução n ${ }^{\circ}$ 5, de 12 de novembro de 1979. Estabelece normas, duração e carga horária dos programas [acesso em 12 set 2018]. Disponível em: http:// portal.mec.gov.br/sesu/arquivos/pdf/CNRM0579.pdf.
6. Brasil. Lei $\mathrm{n}^{\circ}$ 6.932, de 7 de julho de 1981. Dispõe sobre as atividades do médico residente, e dá outras providências. Diário Oficial da União 9 jul 1981; Seção 1, p. 12789.

7. Ribeiro MAA. Apontamentos sobre residência médica no Brasil. Brasília: Câmara dos Deputados, Consultoria Legislativa; 2011. [acesso em 12 set 2018] Disponível em: https://www2.camara.leg. br/atividade-legislativa/estudos-e-notas-tecnicas/publicacoes-daconsultoria-legislativa/areas-da-conle/tema11/2011_123.pdf.

8. Silva P. Saúde financia mais de 1.370 novas bolsas de residência médica. Ministério da Saúde, 15 mar 2016 [acesso em $1^{\circ}$ fev 2018]. Disponível em: http://www.saude.gov.br/noticias/agencia-saude/22637-saudefinancia-mais-1-370-novas-bolsas-de-residencia-medica.

9. Michel JLM, Junior AL, Santos RA, Oliveira RAB, Rebelatto JR, Nunes NPT. Residência médica no Brasil: panorama geral das especialidades e áreas de atuação reconhecidas, situação de financiamento público e vagas oferecidas. Cad ABEM 2011;7:13-27. [acesso em 12 set 2018] Disponível em: https://website.abem-educmed.org.br/wp-content/ uploads/2019/09/CadernosABEM_Vol07.pdf.

10. Nunes MPT, Michel JLM, Haddad E, Brenelli SL, Haddad DM, Ribeiro ECO, et al. Distribuição de vagas de residência médica e de médicos nas regiões do país. Cad ABEM 2011;7:28-34. [acesso em 12 set 2018] Disponível em: https://website.abem-educmed.org.br/wpcontent/uploads/2019/09/CadernosABEM_Vol07.pdf.

11. Sistema Eletrônico do Serviço de Informações ao Cidadão [acesso em 12 set 2018]. Disponível em: https://esic.cgu.gov.br/sistema/site/index.aspx

12. Brasil. Comissão Nacional de Residência Médica. Resolução $n^{\circ}$ 2, de 17 de maio de 2006. Dispõe sobre requisitos mínimos dos Programas de Residência Médica e dá outras providências [acesso em 8 nov 2018]. Disponível em: http://portal.mec.gov.br/dmdocuments/ resolucao02_2006.pdf.

13. Pontifícia Universidade Católica de São Paulo. Faculdade de Ciências Médicas e da Saúde. COREME. Regulamento da Residência Médica de Ginecologia e Obstetrícia. Sorocaba: PUC-SP, FCMS, Coreme; 2016.

14. Cochran WG. Sampling techniques. 3rd ed. New York: John Wiley; 1977. 15. Bardin L. Análise de conteúdo. São Paulo: Edições 70; 2011.

16. Carlomango MC, Rocha LC. Como criar e classificar categorias para fazer análise de conteúdo: uma questão metodológica. Rev. eletrôn. ciênc. pol. 2016;7(1)173-88.

17. Brasil. Ministério da Educação. Proposição de Conteúdo dos Programas de Residência Médica (Resolução nº 2, de 17 de maio de 2006) [acesso em 10 set 2018]. Disponível em: https://abhheventos.com.br/forum2017/ wp-content/uploads/2016/12/projeto-conteudos2.pdf.

18. Hamamoto Filho PT, Oliveira CC, Silva LA, De Carvalho LR, Peraçoli JC, Borges VTM. Feedback de usuários como subsídio para avaliação do estudante de medicina. Rev. bras. educ. med. 2012;36(3)381-86.

19. Botti SHO, Rego STA. Docente-clínico: o complexo papel do preceptor na residência médica. Physis (Rio J.) 2011;21(1):65-85.

20. Liu GKH, De Pontes MVCG, Silva KV, Mandia TM, de Sá BL, Valladão Júnior JBR. Experiências com estágios externos na Residência de Medicina de Família e Comunidade da Faculdade de Medicina da Universidade de São Paulo. Rev. bras. med. fam. comunidade 2018;13(40):1-7.

21. Botti SH, Rego S. Processo ensino-aprendizagem na residência. Rev. bras. educ. med. 2010;34(1):132-40. 
22. Coeck C, Jorens PG, Vandevivere J, Mahler C. ACTH and cortisol levels during residency training. N. Engl. j. med.1991;325(10)738.

23. Levey RE. Sources of stress for residents and recommendations for programs to assist them. Acad. med. 2001;76(2):142-50.

24. Marques RC, Martins Filho ED, De Paula GS, Dos Santos RR. Assédio moral nas residências médica e não médica de um hospital de ensino. Rev. bras. educ. med. 2012;36(3):401-6.

25. Conselho Regional de Medicina do Estado de São Paulo. Assédio moral. São Paulo: Cremesp; 2017 [acesso em $12 \mathrm{dez}$ 2018]. Disponível em: http://www.cremesp.org.br/pdfs/CARTILHA-Assedio-Moral-p5.pdf.

26. Richman JA, Flaherty JA, Rospenda KM, Christensen ML. Mental health consequences and correlates of reported medical student abuse. JAMA 1992;267(5):692-4.

27. Brasil. Comissão Nacional de Residência Médica. Resolução n ${ }^{\circ} 1$, de 16 de junho de 2011. Dispõe sobre o estabelecimento e condições de descanso obrigatório para o residente que tenha cumprido plantão noturno [acesso em 21 nov 2018]. Disponível em: http://portal.mec.gov.br/ index.php?option $=$ com_docman\&view $=$ download $\&$ alias $=8948$-res cnrm-01-2011-1\&category_slug=setembro-2011-pdf\&Itemid=30192.

28. Barrozo SG, Rangel M, Barrozo PRM, Lasmar RB, Oliveira MAP, Dias R. Uma proposta para ensino de videoendoscopia ginecológica em nível de pós-graduação. Femina 2005;33(6):423-7.

29. Borges MC, Miranda CH, Santana RC, Bollela VR. Avaliação formativa e feedback como ferramenta de aprendizado na formação de profissionais da saúde. Medicina (Ribeirão Preto) 2014;47(3):324-31.

30. Nunes MPT, Martins ACS, Machado VR. Avaliação do Sistema RM: instituição, programa, residente, corpo docente. Cad ABEM 2011;7:41-56.

31. Nunes MPT, Michel JLM, Haddad AE, Brenelli SL, Oliveira RAB. A residência médica, a preceptoria, a supervisão e a coordenação. Cad ABEM 2011;7:35-40.

32. Meurer GH, Kozuki H, De Oliveira Filho GR. Avaliação do interesse na carreira acadêmica dos médicos em especialização em anestesiologia. Rev. bras. anestesiol. 2010;60(6):567-76.

33. Reck SJ, Stratman EJ, Vogel C, Mukesh BN. Assessment of residents' loss of interest in academic careers and identification of correctable factors. Arch. dermatol. 2006;142(7):855-8.

\section{CONTRIBUIÇÃO DAS AUTORAS}

Natalia Romano Sanchez e Cibele Isaac Saad Rodrigues contribuíram na concepção e no desenho do estudo, na análise e interpretação dos dados, na análise estatística e na redação do artigo.

Natalia Romano Sanchez contribuiu na coleta de dados e foi a responsável geral pelo estudo.

Cibele Isaac Saad Rodrigues contribuiu na revisão crítica do estudo e foi a responsável pela aprovação final do artigo.

\section{CONFLITO DE INTERESSES}

As autoras declaram não haver conflito de interesses neste estudo.

\section{ENDEREÇO PARA CORRESPONDÊNCIA}

Natalia Romano Sanchez.

Rua Capitão Grandino, 380/1104, Sorocaba, São Paulo, SP, Brasil. CEP: 18040-560.

E-mail: nataliasanchez.med@gmail.com 